\title{
Unpacking the Black Box of Lexical Inferencing: Briefing the Factors Affecting L2 Learners' Lexical Inferencing
}

\author{
Zahra Mohebbi \\ Ministry of Education, Ardabil, Iran \\ Hassan Mohebbi \\ English Department, Faculty of Foreign Languages \\ University of Tehran, Tehran, Iran \\ hassanmohebbi@ut.ac.ir
}

\begin{abstract}
Lexical inferencing (LIF) is one of the major strategies which second language (L2) learners resort to in performing reading tasks and L2 vocabulary learning. However, the majority of $L 2$ learners are not able to make accurate LIF due to different factors which have effect on an L2 learner's ability of successful LIF. The present paper aims at unpacking the black box of LIF. Therefore, this study briefs the factors which play key roles in LIF, in particular reader- and textbased factors. Reader-based factors include L2 proficiency, L2 vocabulary knowledge, paying attention to details, cognitive and mental effort of L2 learners, L2 grammar knowledge, and background knowledge. Moreover, textbased factors are Word characteristics, text characteristics, the presence of contextual clues, and topic familiarity. Additionally, the implications and suggestions for future $\mathrm{L} 2$ research are discussed in detail.
\end{abstract}

Key Words: L2 vocabulary learning; Reading comprehension; Lexical inferencing

\section{INTRODUCTION}

In recent years, there has been a growing interest in second language (L2) vocabulary learning. A considerable body of L2 research exists on the effectiveness of various teaching and learning methods of L2 vocabulary than there was twenty years ago (Nation, 2011). L2 vocabulary learning is of particular interest because misinterpretations of lexical items are key elements in global errors that restrain communication (Crossley et al., 2009). Given vocabulary learning as a fundamental task in second language acquisition (SLA), Zhang and Li (2011) argue that SLA skills, namely speaking, reading, listening, and writing all build on L2 learners' lexical repertoire.

In a recent study, Schmitt et al. (2011) came to this conclusion that for comprehending a text, L2 learners are required to know 98 percent of its lexical items. The results of the study conducted by Prichard and Matsumoto (2011) indicated that even participants who knew 9095 percent of lexical items of the text had difficulty comprehending the text. Laufer and Ravenhorst-Kalovski (2010) suggest an optimal L2 vocabulary threshold, which is mastering 8000 word families which results in 98 percent coverage of lexical items of texts. Learning such a large number of lexical items is one of the greatest hurdles which L2 learners encounter in SLA (Schmitt, 2010). This bulk of vocabulary cannot be taught directly. As Nation (1982) asserts, the majority of L2 vocabulary learning is indirect. In fact, incidental vocabulary learning is the main vehicle for learning new lexical items. Kim (2011) argues that L2 teachers are fully aware of the difficulty of mastering vast numbers of L2 vocabulary learning, but might 
not know how effectively assist L2 learners in this endeavor. Hence, from a pedagogical point of view, Kim underscores the need for SLA research that helps to identify the types of learning task that provide optimal opportunities for L2 vocabulary learning. For meeting this need, i.e., learning a large number of new lexical items, L2 learners should be exposed to a great amount of reading. It is generally accepted that L2 reading is the primary way that L2 learners can resort to it beyond the classroom to expand their lexical repertoire (Schmitt et al., 2011). It is clear that in reading a text, L2 learners come up with some words they do not know, which lead them to frustration and it hampers comprehension. lexical inferencing (LIF) is one of the major strategies which L2 learners fall back on when they encounter unfamiliar words during reading (e.g., de Bot et al., 1997; Deschambault, 2011; Na \& Nation, 1985; Paribakht, 2004, 2005; Schmitt, 2008; Wesche \& Paribakht, 2010). Importantly, Wesche and Paribakht (2010) claim that LIF is the only tool which L2 learners might have recourse to facing unknown lexical items. LIF is defined as making informed guesses about the meaning of an unknown word during reading comprehension on the basis of linguistic and non-linguistic cues and different aspects of the learner's knowledge at hand (Qian, 2005). LIF, hence, is a cognitive strategy through which an L2 learner employs contextual cues and his or her background knowledge to infer the meaning of an unknown word in a text (Wesche \& Paribakht, 2010).

However, LIF is not simply a straightforward process, but there are reader-based and textbased factors which affect the success of LIF. Consequently, the rate of successful LIF is not significant and L2 learners often make erroneous LIF. In the present paper, we elaborate on the factors which play key roles in L2 learners' ability to accomplish successful LIF. Furthermore, we offer some new venues of L2 research in this field which might shed light on enhancing the rate of effective LIF in L2 reading tasks.

\section{Taxonomies of L2 learners' knowledge sources in LIF}

Wesche and Paribakht (2010) (Table 1) presented a taxonomy which summarizes all the knowledge sources in carrying out LIF. The taxonomy is on the basis of word, sentence, and discourse and the fourth major category is the non-linguistic knowledge.

\section{Factors Affecting the Success of LIF}

Success or failure in reading comprehension is affected by specific reader characteristics, text properties, and the context in which reading takes place (Kendeou et al., 2011). L2 reading is a complex cognitive activity, which involves simultaneous linguistic processing such as pattern recognition, letter identification, lexical access, concept activation, syntactic analysis, propositional encoding, sentence comprehension, and intersentence integration, as well as activating prior knowledge, storing information, and monitoring comprehension (Pulido, 2007b). As already highlighted, the variables which play key roles in LIF might be classified as reader-based variables and text-based variables. In this section, we turn to these variables brief them.

\section{Reader-based Variables \\ L2 proficiency}

Mostly, L2 learners at different L2 proficiency levels encounter words which seem unfamiliar. Therefore, they need to be equipped with effective strategies, in particular LIF to decode the meaning of an unfamiliar lexical item. SLA research carried out in this vein has reported that beginning and advanced learners resort to LIF more than intermediate learners (Barnett, 1989, as cited in Kaivanpanah \& Alavi, 2008b). As Haastrup (1991, as cited in Wesche and Paribakht, 2010) argued, it seems to be a threshold level of proficiency that L2 learners ought to reach first before they can employ effective LIF procedures. 
Table1: Wesche and Paribakht trilingual study taxonomy of knowledge source use in L1 and L2 LIF

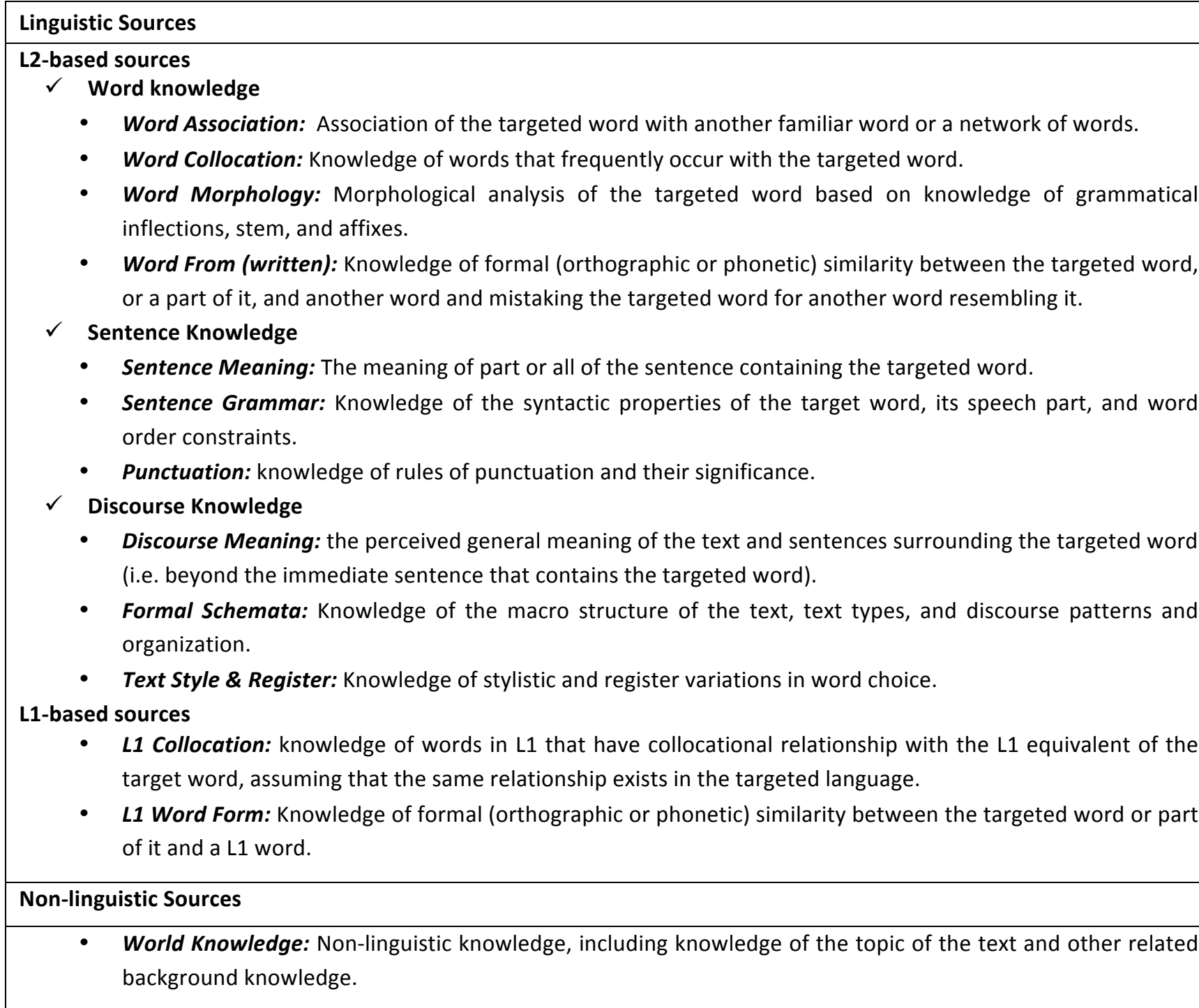

\section{L2 vocabulary knowledge}

As discussed earlier, L2 learners are required to master at least 98 percent of a text's lexical items to carry out $\mathrm{L} 2$ reading comprehension tasks successfully. Therefore, learners' lexical repertoire has an effect on the success of LIF in reading tasks (Kaivanpanah \& Soltani Moghaddam, 2012; Nassaji, 2003; Nassaji 2004). In fact, most of time L2 learners are not able to this satisfactory point, so relying on learners' L2 vocabulary knowledge does not stand to reason.

\section{Attention to details}

For a successful LIF, L2 learners should focus on details to infer the meaning of an unknown word from a text. As L2 teachers, we have witnessed that L2 learners avoid putting enough energy on decoding the texts and LIF. It is worth noting here, high analytic ability learners might outperform low analytic ability learners in LIF.

\section{Cognitive and mental effort}

L2 Learners' cognitive and mental effort might influence the success of LIF. According to the involvement load hypothesis (Hulstijn \& Laufer, 2001) LIF and L2 vocabulary learning depends on the amount of involvement in processing these lexical items. Pulido (2003) rightly stressed 
that L2 research indicated that easily inferred words might not lead to deep learning due to the lack of a need to pay enough attention to the new words.

\section{L2 grammar knowledge}

L2 grammar knowledge plays a crucial role in SLA. It also exerts an influence on LIF. The findings of the study conducted by Paribakht (2004) revealed that L2 learners often employ their L2 grammar knowledge in LIF. Similarly, Kaivanpanah and Alavi (2008a) emphasized that L2 grammar knowledge exerts a significant impact on LIF.

\section{World knowledge/background knowledge}

L2 learners might take advantage of their background knowledge to make accurate LIF. Background knowledge is argued to be the first important facilitative factor in L2 reading (Hauptman, 2000). Top-down processes in L2 reading and LIF imply that L2 learners might elaborate the text in their minds and incorporate the extracted meaning into their own knowledge and view of the world, their knowledge structures, and their own schemata (Macaro \& Erler, 2008). The findings of SLA research with respect to L2 learners' background knowledge has made clear its positive effect on L2 reading comprehension (Lesser, 2007). Background knowledge, brought by the L2 reader to the text, interacts with text information to foster comprehension and LIF and aids subsequent recall; text information that is consistent with L2 learner's background knowledge might be easier than information which is unfamiliar (Burgoyne, 2011). Pulido (2007b) concludes "in sum, the construction of a coherent mental representation of a text involves the interaction between explicitly stated textual information and background knowledge." (p. 185)

\section{Text-based Variables}

\section{Word characteristics}

Nation (2001, as cited in Schmitt, 2010) summarizes what is involved in knowing a word. According to him, knowing a word involves form (spoken, written, word parts), meaning (form and meaning, concept and referents, and associations) and use (grammatical functions, collocations, and constraints on use such as register and frequency). Learning a new lexical item involves an ongoing elaboration of knowledge about that lexical item itself and the ability to employ it (Wesche \& Paribakht, 2000). Therefore, as L2 learners master different aspects of a lexical item, they are more likely to come up with accurate LIF.

\section{Text characteristics}

The level of text difficulty has an impact on driving the meaning of an unknown word. There should be a balance between an L2 learner's proficiency and a text's difficulty. Use of less frequent, specialized, and abstract lexical items, the amount of relativization/embedding, and sentence length are just some of the crucial factors that make texts difficult (Kaivanpanah \& Alavi, 2008b).

\section{The presence of contextual clues}

The presence of clear linguistic and semantic clues is of primary importance in facilitating successful LIF (Kaivanpanah \& Alavi, 2008b). Sternberg and Powell (1983, as cited in Bengeleil \& Paribakht, 2004) discuss the mediating variables for each context that determine how efficiently L2 learner would be able to take advantage of available/accessible contextual cues. They touch upon the external context, i.e., context beyond the lexicon itself, the meaning of an unknown lexical item is more likely to be driven if it occurs several times in a different contexts within the text, if it is a key word, and if the context provides sufficient cues. Also, they discuss the internal context, namely the lexical item itself, unknown lexical items in the text that can be analyzed into perceivable morphemes might enhance the possibility of successful LIF based on 
morphology. Frantzen (2003) states that L2 learners should be advised to have a rational skepticism with respect to dependability of contexts due to the fact that they can imply a variety of meanings.

\section{Topic familiarity}

If the topic of a text given is unfamiliar, abstract, or too technical, L2 learners might face difficulty in performing LIF (Kaivanpanah \& Alavi, 2008b; Pulido, 2007a). In contrast, a text that is in the domain of an L2 learner's familiar topic would be much easier.

\section{CONCLUDING REMARKS}

It is imperative to stress that LIF, as a major strategy in L2 reading and vocabulary learning, might not be undermined due to L2 learners' insignificant rate of successful LIF. To date, the findings of L2 research investigating different aspects of LIF endorse that L2 learners go under a difficult experience in carrying out LIF because of the different factors which play crucial roles in LIF. Wesche and Paribakht (2010) underscored the fact that LIF is a demanding task which L2 learners need to perform. Hence, L2 researchers need to examine the ways that might enhance LIF.

The present paper aimed at highlighting and briefing factors which have an effect on LIF. Further research is needed to throw more light on the factors might influence the effectiveness of LIF. L2 researchers and practitioners should examine the techniques which might enhance the insignificant rate of successful LIF. To my best knowledge, there is a lack of empirical L2 research, if there is any, to illustrate the effect of collaborative tasks on prompting LIF. In addition, it is imperative to mention that pre-task modeling might be effective in disentangling LIF. It might be assumed that L2 learners might take advantage of LIF pre-task modeling in carrying out successful LIF.

\section{References}

Bengeleil, N. F., \& Paribakht, T. S. (2004). L2 reading proficiency and lexical inferencing by university EFL learners. The Canadian Modern Language Review, 61(2), 225-249.

Burgoyne, K., Whiteley, H. E., \& Hutchinson, J. M. (2011). The role of background knowledge in text comprehension for children learning English as an additional language. Journal of Research in Reading, 3(2), $1-17$.

Crossley, S., Salsbury, T., \& McNamara, D. (2009). Measuring L2 lexical growth using hypernymic relationships. Language Learning, 59(2), 307-334.

de Bot, K., Paribakht, T. S., \& Wesche, M. B. (1997). Toward a lexical processing model for the study of second language vocabulary acquisition. Studies in Second Language Acquisition, 19, 309-329.

Deschambault, R. (2011). Thinking-aloud as talking-in-interaction: Reinterpreting how L2 lexical inferencing gets done. Language Learning, $X X(X), 1-36$.

Frantzen, D. (2003). Factors affecting how second language Spanish students derive meaning from context. The Modern Language Journal, 87(2), 168-199.

Hauptman, P. C. (2000). Some hypotheses on the nature of difficulty and ease in second language reading: An application of schema theory. Foreign Language Annals, 33(6), 622-631.

Hulstijn, J. H., \& Laufer, B. (2001). Some empirical evidence for the involvement load hypothesis in vocabulary acquisition. Language Learning, 51, 539-558. 
Kaivanpanah, S., \& Alavi, S. M. (2008a). The role of linguistic knowledge in word-meaning inferencing. System, 36, 172-195.

Kaivanpanah, S., \& Alavi, S. M. (2008b). Deriving unknown word meaning from context: Is it reliable? RELC Journal, 39(1), 77-95.

Kaivanpanah, S., \& Soltani Moghaddam, M. (2012). Knowledge sources in EFL learners' lexical inferencing across reading proficiency levels. RELC Journal, 43(3), 373-391.

Kendeou, P., Muis, K. R., \& Fulton, S. (2011). Reader and text factors in reading comprehension processes. Journal of Research in Reading, 34(4), 365-383.

Kim, Y. J. (2011). The role of task-induced involvement and learner proficiency in L2 vocabulary acquisition. Language Learning, 61(1), 100-140.

Laufer, B., \& Ravenhorst-Kalovski, G. C. (2010). Lexical threshold revisited: Lexical text coverage, learners' vocabulary size and reading comprehension. Reading in a Foreign Language, 22(1), 15-30.

Leeser, M. J. (2007). Learner-based factors in L2 reading comprehension and processing grammatical form: Topic familiarity and working memory. Language Learning, 57(2), 229-270.

Macaro, E., \& Erler, L. (2008). Raising the achievement of young-beginner readers of French through strategy instruction. Applied Linguistics, 29(1), 90-119.

Na, L. \& Nation, I. S. P. (1985). Factors affecting guessing vocabulary in context. RELC Journal, 16, 33-42.

Nassaji, H. (2003). L2 vocabulary learning from context: strategies, knowledge sources, and their relationship with success in L2 lexical inferencing. TESOL Quarterly, 37(4), 645-670.

Nassaji, H. (2004). The relationship between depth of vocabulary knowledge and L2 learner's lexical inferencing strategy use and success. The Canadian Modern Language Review, 61(1), 107-134.

Nation, I. S. P. (1982). Beginning to learn foreign vocabulary: A review of the research. RELC Journal, 13, 1436.

Nation, I. S. P. (2011). Research into practice: Vocabulary. Language Teaching, 44(4), 529-539.

Paribakht, T. S. (2004). The role of grammar in second language lexical processing. RELC Journal, 35(2), 149160.

Paribakht, T. S. (2005). The influence of first language lexicalization on second language lexical inferencing: A study of Farsi-speaking learners of English as a foreign language. Language Learning, 55(4), 701-748.

Prichard, C., \& Matsumoto, Y. (2011). The effect of lexical coverage and dictionary use on L2 reading comprehension. The Reading Matrix, 11(3), 207-225.

Pulido, D. (2003). Modeling the role of second language proficiency and topic familiarity in second language incidental vocabulary acquisition through reading. Language Learning, 53(2), 233-284.

Pulido, D. (2007a). The effects of topic familiarity and passage sight vocabulary on L2 lexical inferencing and retention through reading. Applied Linguistics, 28(1), 66-86.

Pulido, D. (2007b). The relationship between text comprehension and second language incidental vocabulary acquisition: A matter of topic familiarity? Language Learning, 57(1), 155-199.

Qian, D. D. (2005). Demystifying lexical inferencing: The role of aspects of vocabulary knowledge. TESL Canada, 22(2), 34-54.

Schmitt, N. (2008). Review article: Instructed second language vocabulary learning. Language Teaching Research, 12, 329-363.

Schmitt, N. (2010). Researching vocabulary: A vocabulary research manual. New 
York: Palgrave Macmillan.

Schmitt, N., Jiang, X., \& Grabe, W. (2011). The percentage of words known in a text and reading comprehension. The Modern Language Journal, 95(1), 26-43.

Wesche, M. B., \& Paribakht, T. S. (2010). Lexical inferencing in a first and second language: Cross-linguistic dimensions. Toronto: Multilingual Matters.

Zhang, B., \& Li, C. (2011). Classification of L2 vocabulary learning strategies: Evidence from exploratory and confirmatory factor analyses. RELC Journal, 42(2), 141-154. 